confirmation of Mr. Harrison's published account of the finding of the limestone tablet. If this evidence leads to the conclusion that these relics are modern productions, as I believe it does, there is no necessity for the present of 'further investigation,' - a conclusion Mr. MacLean seems to have reached while writing his 'Mound-builders.' Crrus Thomas.

\section{The claimed wheat and rye hybrid.}

In Science of Jan. 15 appears an article from Dr. Sturtevant, which, to save words, I will call a criticism of an account of my rye and wheat hybrids, published in the Century magazine of last January by Charles Barnard. Mr. Barnard, after an examination of the plants at my place last summer, gives their history, accepting, without question, their hybrid origin. Dr. Sturtevant, who also examined them last summer, begs to dissent. He considers the evidence adduced only 'sufficient to establish grave doubts.'

While we were on our way to the plots, Dr. Sturtevant remarked that he wanted me to know that he was 'incredulous as to the whole thing.' While we were returning, he said, "I am convinced that they are hybrids, but I question whether they will not be found to be distinctly either wheat or rye." In the Science article referred to, he next states that he has compared the pictures of a few of these heads which appeared in the Rural New-Yorker with those of five old varieties which he mentions, and finds them closely alike. Then he remarks that he does not question the 'attempt at a cross.' The 'variability effected is,' he admits, ' indicative of a foreign pollen.' This variability, which he believes not to be due to hybridization, the doctor explains by an 'hypothesis.' It is that under the stimulus of the rye pollen, atavism has resulted, whereby varieties dormant in the wheat (female) plant have made their appearance. Finally he expresses the hope that some one, expert in agricultural botany, may 'investigate a series of these specimens.'

Dr. Sturtevant, though he states that he has carefully studied the 'published claims,' has apparently overlooked the published fact that specimens of these hybrids have been sent to no less than six wellknown botanists, several of whom have replied that they were evidently hybrids, while others replied to the effect that the hybridization was a most interesting fact, etc.

Now, if we emasculate the florets of a head of wheat while the anthers are immature, and repeatedly apply rye pollen, and thus succeed in attaining ten grains, from which; in three years, at least fifty different varieties appear, differing as widely as any known wheats differ from each other, while some of them resemble rye more than wheat, can anyone reasonably doubt that a hybridization was effected ? Why assume any thing else whatever? What does Dr. Sturtevant mean by ascribing such changes to the 'stimulus of foreign pollen' as something different from the sexual effect of foreign pollen? Suppose atavism is shown in some of these : does it not prove, all the same, that hybridization was effected? A hybrid may show all, some, or none of the characteristics of either parent, and still be a hybrid, as has often been revealed in the later seedling progeny.

In drawing resemblances between the pictures in the Rural New-Yor'cer and those of which he speaks, the doctor, very likely, forgets an important fact; viz., that in many of the heads of the plants most resembling rye, the spikelets bear but two kernels, while many are wholly abortive. Again : the botanical relationship is marked not only by narrower glumes, by fewer florets and grains, but by the fact that the culms beneath the head for an inch or so are hairy, - a characteristic that never-occurs on wheat culms. The color of both the culms and leaves is also distinctly lighter (more glaucous) than that of wheat, and the habit of the young plant is that of rye.

E. S. Carman.

\section{A recent ice-storm.}

The trees in central Massachusetts, along the line of the Boston and Albany railroad from Worcester to Spencer, suffered severely from the weight of ice formed upon them during the storm of Feb. 11-13, that caused the recent destructive floods. It was noticeable that the trees which exposed the largest surface for the attachment of ice did not suffer most : the pines with their green needles, and the oaks with their dead leaves, generally escaped injury; and the slender birches were saved by bending instead of breaking. But from five to twenty per cent of the other deciduous trees were more or less hurt. The side limbs were not often broken: it was nearly always the vertical top-stems that sustained the most injury, apparently because their natural position was farthest from that into which the weight of the clinging ice forced them.

Can some of your readers furnish direct observational evidence to show why the pines and leafy oaks escaped, while the bare trees were so much damaged? Cambridge, Feb. 20. W. M. Davis.

\section{Corrections of thermometers for pressure.}

If any of your readers interpreted our reference in Science, Feb. 12, to a letter from the signal ofice, as your correspondent, Sig., feared they might do, we regret it, and are glad that the import of that letter has been fully explained. We are well aware that many of our text-books on heat refer to the effect of pressure on the thermometer, and state how to prevent it in some instances. The effect of appreciable changes of pressure on the thermometer seemed to us to be sufficient to demand correction in all accurate thermometric work. If such corrections are generally made, they are omitted in the report of experiments.

F. P. Venable.

University of North Carolina, Feb. 22.

$$
\text { J. W. GoRe. }
$$

\section{Is the dodo an extinct bird?}

Referring to Dr. Shufeldt's article (Science, vii. 145) respecting the supposed present existence of the dodo, it may be desirable to state, for the benefit of those who are not already aware of the fact, that the so-called dodo from Samoa, mentioned in the clipping ' from an English newspaper,' is not the dodo at all, but the dodo-pigeon, Didunculus strigirostris, a living specimen of which was last year presented to the national museum by Dr. T. Canisius, ex-consul of the United States at Samoa. This specimen was, at latest account, thriving in the zoölogical garden at Philadelphia. ROBERT RIDGWAY.

Smithson. inst., Feb. 15. 